\title{
Supportive communication with parents moderates the negative effects of electronic media use on life satisfaction during adolescence
}

\author{
Meyran Boniel-Nissim • Izabela Tabak • Joanna Mazur • Alberto Borraccino • \\ Fiona Brooks • Rob Gommans • Winfried van der Sluijs • Emese Zsiros • \\ Wendy Craig • Yossi Harel-Fisch • Emily Finne
}

Received: 14 July 2014/Revised: 8 December 2014/Accepted: 13 December 2014/Published online: 31 December 2014

(C) Swiss School of Public Health 2014

\begin{abstract}
Objectives To examine the impact of electronic media
(EM) use on teenagers' life satisfaction (LS) and to assess
the potential moderating effect of supportive communica-
Abstract
Objectives To examine the impact of electronic media
(EM) use on teenagers' life satisfaction (LS) and to assess
the potential moderating effect of supportive communica-

Abstract
Objectives To examine the impact of electronic media
(EM) use on teenagers' life satisfaction (LS) and to assess
the potential moderating effect of supportive communica-

Abstract
Objectives To examine the impact of electronic media
(EM) use on teenagers' life satisfaction (LS) and to assess
the potential moderating effect of supportive communication with parents (SCP).

Methods Data were drawn from the cross-national Health Behaviour in School-aged Children (HBSC) study (2009/ 2010) in Canada, England, Germany, Hungary, Italy, Israel, The Netherlands, Poland and Scotland. Sample size: 53,973 students aged $11-15$ years.

Results More hours per day spent on the computer were associated with lower LS; more EM communication with friends with higher LS. This relationship became negative
\end{abstract}

This article is part of the special issue "Communication Technology, Media Use and the Health of Our Kids".

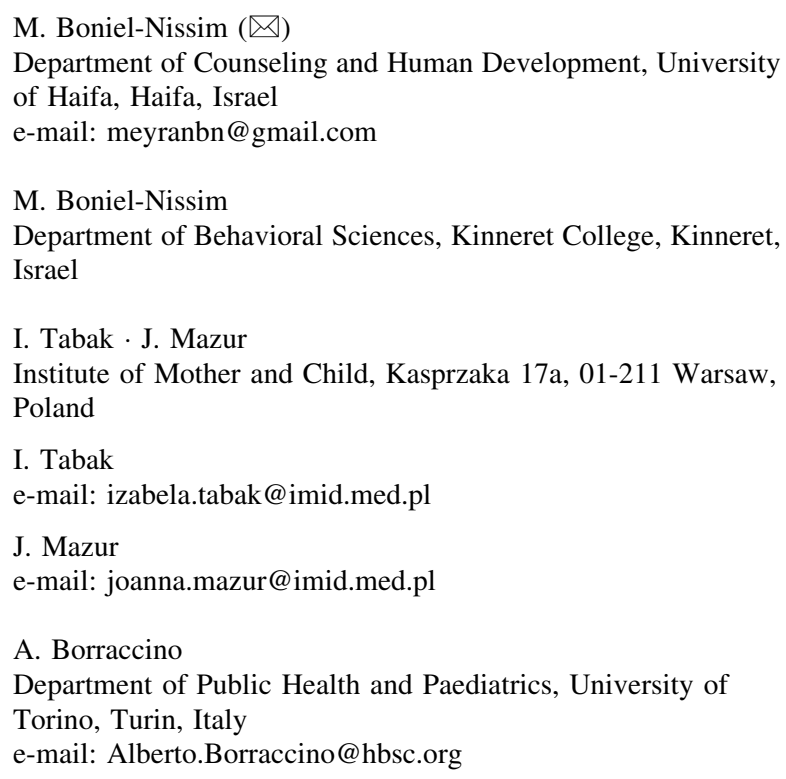
if EM use reached and exceeded a certain threshold. SCP moderated the effect of EM communication with friends, but not computer use for the total sample. SCP seems to be more important than computer use or EM communication with friends for LS and it seems to buffer negative effects of EM use.

Conclusions Communication with parents seems to buffer the negative effects of EM use on LS during adolescence. Higher computer use was related to lower LS, but "optimal" frequency of EM communication with friends was country specific.

Keywords Life satisfaction - Adolescents ·

Computer use - Supportive communication with parents . Cross-national study

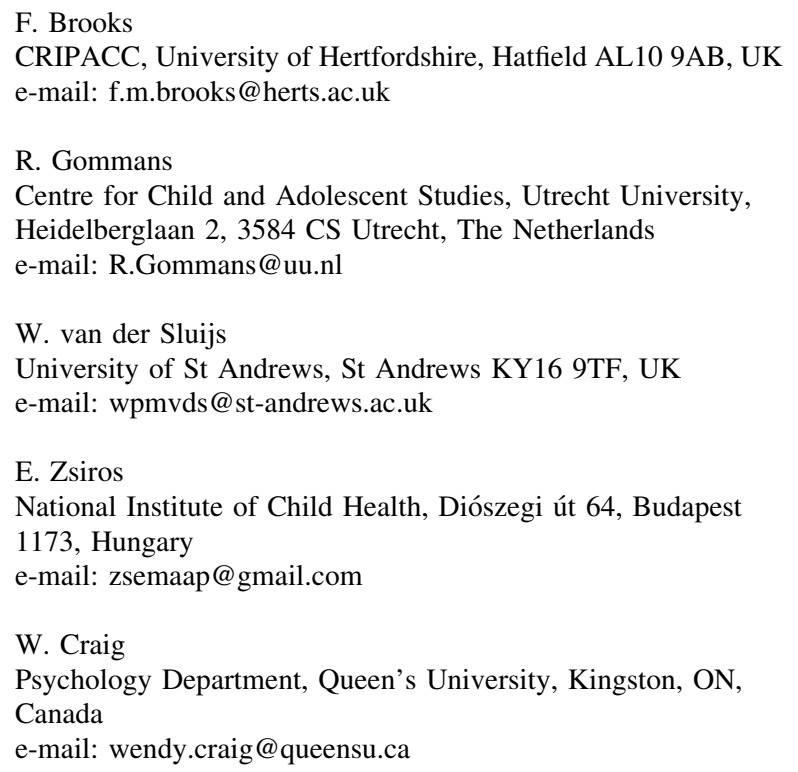




\section{Introduction}

Adolescents' use of electronic media

The current generation of young people entering adolescence, electronic media (EM) is a central part of their lives. Recent data indicate that $95 \%$ of teenagers in the USA aged 12-17 use the internet (Purcell 2013), and they spend up to $7 \mathrm{~h}$ a day in screen-based activities (Benson 2011). Data from the EU Kids Online study show that European 9-16-year-olds spend an average of $88 \mathrm{~min} /$ day online (Livingstone et al. 2011). Seven in ten UK children aged 5-15 have access to a tablet computer at home, and four in ten children aged 5-15 own a mobile phone, rising to almost eight in ten children aged 12-15 (Ofcom 2014).

EM use can positively influence social aspects of adolescent lives such as easiness to communicate with peers and number of friends (Valkenburg and Peter 2009; Kuntsche et al. 2009), as well as have a positive impact on spatial skills (Uttal et al. 2013), cognitive development, like reading skills (Johnson 2010) and even contribute to the development of resilience (Sweetser and Wyeth 2005). There is also strong evidence, however, that EM use may be related to a variety of problem behaviors in adolescence, such as internet addiction (Adiele and Olatokun 2014), shortened sleep duration, poorer diet quality, lower physical activity levels, weight gain (Jackson et al. 2011; Chahal et al. 2013), poor school performance (Mößle et al. 2010), loneliness (Deniz 2010), depression and social anxiety symptoms (Becker et al. 2013), and increased likelihood of physical complaints (Torsheim et al. 2010).

The goal of the current study was to examine the impact of EM use on young people's subjective life satisfaction.

Life satisfaction and the role of electronic media use

Life satisfaction (LS) is one component of subjective wellbeing, consisting of the existence of positive affect, the absence of negative affect, and the cognitive judgment of satisfaction with life as a whole (Diener et al. 1985). LS is positively related to mental and physical health as well as health behaviors in adolescents. LS is furthermore associated with material and housing circumstances, and

\footnotetext{
Y. Harel-Fisch

Bar Ilan University, Ramat Gan, Israel

e-mail: harelyos@netvision.net.il

E. Finne

WHO Collaborating Centre for Child and Adolescent Health Promotion, School of Public Health, Bielefeld University, Universitätsstraße 25, 33615 Bielefeld, Germany

e-mail: emily.finne@uni-bielefeld.de
}

negatively related to risk behaviors like substance use or violent behaviors (Park 2004; Bradshaw et al. 2011).

Previous analyses of the international HBSC study showed that the total amount of screen-based media use (i.e., television and computer use) was related to lower LS, more health complaints, risk behaviors, and poorer family relationships but with better peer relationships among adolescents from North America and Europe (Iannotti et al. 2009). In other studies, screen time was negatively related to overall quality of life in Australian and German adolescents (Mathers et al. 2009; Lacy et al. 2012; Finne et al. 2013).

Stepanikova et al. (2010) showed that the amount of time spent online (web, instant messaging, chat rooms, newsgroups) was negatively associated with LS and positively associated with loneliness. The amount of electronic media communication (EMC; e-mail, chat, texting and phone use) also was significantly related to more psychological, physical and attentional problems in US adolescents (Rosen et al. 2014). In another study, higher use of different forms of EMC also were related to lower LS (Ferguson et al. 2014), while in a study by Valkenburg and Peter (2007) it seemed to foster friendship quality, which in turn led to higher LS in adolescents.

Life satisfaction and the role of parents

Adolescence brings changes in family relationships, as teenagers become more independent (Steinberg and Morris, 2001). The discrepancy between parents and their children in the use of EM can weaken their relationship (Mesch, 2003). Recent research, however, has identified that quality of communication between adolescents and parents remains of significance and operates as important protective health assets (Brooks et al. 2012).

A Hungarian study found that talking about problems with parents was positively associated with LS, especially in girls (Piko and Hamvai, 2010). In Canadian and Polish studies, better parent-adolescent communication was significantly related to higher LS (Elgar et al. 2013; Tabak et al. 2013). In Dutch youth, social support from parents was more important in preventing emotional problems than peer support (Helsen et al. 2000). In addition to the potential impact of EM use on young people's subjective LS, the current study also examined to what extent supportive communication with parents (SCP) moderated the link between EM use and LS.

The current study

The first goal of the current study was to investigate the association between adolescents' EM use and their LS. The second goal was to investigate how the quality of communication with parents may interact with different forms of EM 
use to affect teenagers' LS. The third goal of the current study was to examine cross-country differences in these effects.

\section{Method}

Study design and sample

Data were drawn from the cross-national (HBSC) study, collected during the 2009/2010 school year in nine regions: Canada, England, Germany, Hungary, Israel, Italy, The Netherlands, Poland and Scotland. There were 53,973 students aged 11,13 , and 15 years (Table 1) who participated in the study.

Data were collected using a school-based survey administered in the classroom by teachers or trained researchers in each participating region. Requirements in terms of sampling, questionnaire items and survey administration were followed according to the standardized research protocol (Currie et al. 2012). Response rates ranged from 40 (England) to $86 \%$ (Germany) with an average of $60 \%$; each country obtained needed ethical approvals for the survey.

\section{Measures}

\section{Life satisfaction $(L S)$}

Participants were asked to rate their LS using a visual analog scale-the "Cantril ladder" with 10 steps (10 = best possible life; $1=$ worst possible life). Adolescents indicated where on the ladder they would place their life at present. A score of 6 or more indicated high LS (Currie et al. 2012). The item has been used in previous work showing good reliability and significant associations with other well-being measures, and perceived and subjective health (Levin and Currie 2013).

\section{Electronic media communication (EMC) with friends}

Frequency of EMC was measured by asking how often adolescents talk to friend(s) on the phone, send them text messages or have contact through the Internet. Responses were rated on a 5-point scale $(1=$ never or rarely; $5=$ every day). EMC with friends was dichotomised: low $=$ less than every day; high $=$ daily.

\section{Computer use per day}

Frequency of computer use was measured by asking how many hours a day participants usually use the computer for game playing, emailing, internet (on weekdays and at weekend). Responses were rated on a 9-point scale ( $1=$ none at all; $2=$ about half an hour a day; $3=$ about $1 \mathrm{~h}$ a day; $9=$ about 7 or more hours a day). Daily frequency of each behavior was weighted by number of days (5 weekdays and 2 weekend days) and summarized. This variable was dichotomised: low $=0-2 \mathrm{~h} /$ day; high $=$ more than $2 \mathrm{~h}$ /day.

\section{Supportive communication with parents (SCP)}

Participants were asked how easy it is for them to talk to their mother/father about things that really bother them. Responses were rated on 4-point scale ( 1 = very easy; $4=$ very difficult). Reported quality of communication

Table 1 Background characteristics of the sample (\%)

\begin{tabular}{|c|c|c|c|c|c|c|c|c|c|c|}
\hline Variable & $\begin{array}{l}\text { Total } \\
\text { sample } \\
\text { weighted } \\
\text { data }\end{array}$ & $\begin{array}{l}\text { Canada } \\
(n=15,919)\end{array}$ & $\begin{array}{l}\text { England } \\
(n=3,524)\end{array}$ & $\begin{array}{l}\text { Germany } \\
(n=5,070)\end{array}$ & $\begin{array}{l}\text { Hungary } \\
(n=4,864)\end{array}$ & $\begin{array}{l}\text { Israel } \\
(n=4,135)\end{array}$ & $\begin{array}{l}\text { Italy } \\
(n=4,837)\end{array}$ & $\begin{array}{l}\text { Netherlands } \\
(n=4,591)\end{array}$ & $\begin{array}{l}\text { Poland } \\
(n=4,262)\end{array}$ & $\begin{array}{l}\text { Scotland } \\
(n=6,771)\end{array}$ \\
\hline \multicolumn{11}{|l|}{ Gender } \\
\hline Male & 48.0 & 49.1 & 43.5 & 48.5 & 47.3 & 46.3 & 50.1 & 49.1 & 48.8 & 49.3 \\
\hline Female & 52.0 & 50.9 & 56.5 & 51.5 & 52.7 & 53.7 & 49.9 & 50.9 & 51.2 & 50.7 \\
\hline \multicolumn{11}{|l|}{ Age (years) } \\
\hline 11 & 32.4 & 28.6 & 33.8 & 34.0 & 30.8 & 35.7 & 32.9 & 32.8 & 32.9 & 30.5 \\
\hline 13 & 33.7 & 36.8 & 34.3 & 32.9 & 33.0 & 31.4 & 34.9 & 35.0 & 33.9 & 31.4 \\
\hline 15 & 33.8 & 34.6 & 31.9 & 33.1 & 36.2 & 32.9 & 32.1 & 32.2 & 33.2 & 38.1 \\
\hline \multicolumn{11}{|l|}{ Family structure } \\
\hline Intact families & 71.8 & 66.2 & 62.5 & 73.6 & 70.7 & 85.9 & 81.0 & 79.2 & 80.8 & 64.8 \\
\hline Other & 28.2 & 33.8 & 37.5 & 26.4 & 29.3 & 14.1 & 19.0 & 20.8 & 19.2 & 35.2 \\
\hline \multicolumn{11}{|l|}{ Family affluence } \\
\hline Low & 12.7 & 8.2 & 12.7 & 7.8 & 23.4 & 15.1 & 12.6 & 3.9 & 20.4 & 9.6 \\
\hline Middle & 37.8 & 34.6 & 34.4 & 37.0 & 44.3 & 35.2 & 42.9 & 32.1 & 42.9 & 35.8 \\
\hline High & 49.5 & 57.2 & 52.9 & 55.3 & 32.2 & 49.7 & 44.6 & 64.0 & 36.7 & 54.6 \\
\hline
\end{tabular}


with father and mother were dichotomised into two categories: easy (0) and difficult (1), summarized, and again dichotomised: $0=$ easy communication with both parents; $1=$ difficult communication with at least one parent.

\section{Socio-demographic information}

Participants reported their gender and age, family structure (living with both parents or not), and family affluence measured by the family affluence scale, including four items about car and computer ownership, own bedroom and family holidays. Responses were summarized on an 8-point scale $(0-1=$ low affluence; $4-5=$ average affluence; $\quad 6-7=$ high affluence), in accordance with international guidelines (Boyce and Dallago 2004).

\section{Statistical analyses}

Chi-square tests were used to examine the associations between gender, age and country, and categorized independent variables. Mean LS scale scores were compared using univariate ANOVAs. Next, a series of general linear models (GLM) with interaction effects were specified and estimated. Gender, age, family affluence and structure were added as control variables. Computer use, EMC, SCP, and two interaction terms (computer use and EMC by SCP) were added as explanatory variables. Two separate stepwise logistic regression analyses were conducted to further explore the interaction effects on LS (adjusted odds ratios) using a combination of dichotomised SCP and computer use or EMC, respectively, to result in two 4-category variables. The calculations were carried out using SPSS 19. In analyses of the full sample (all countries together), data were weighted by country sample size.

\section{Results}

Most adolescents were satisfied with their life and perceived the communication with their parents as easy, especially boys $\left[\mathrm{LS}: \chi^{2} \quad(1, \quad N=46,921)=162.02\right.$; $p<0.001$; SCP: $\chi^{2}(1, N=42,436)=794.39 ; p<0.001$ ] and younger adolescents [accordingly: $\chi^{2}(1, \quad N=$ $46,513)=157.43 ; \quad p<0.001 ; \quad \chi^{2} \quad(1, \quad N=42,084)=$ $1,108.83 ; p<0.001]$. Every third teenager spent time on the computer consistent with expert recommendations (no more than $2 \mathrm{~h}$ of media time per day, American Academy of Pediatrics 2001). Girls spent less time using the computer than boys $\left[\chi^{2}(1, N=45,863)=727.49 ; p<0.001\right]$ and younger adolescents spent more time using the computer than older adolescents $\left[\chi^{2} \quad(1, N=45,480)=\right.$ $1,312.55 ; p<0.001]$. Moreover, frequency of EMC with peers increased with age $\left[\chi^{2}(1, N=46,875)=3,287.62\right.$; $p<0.001]$.

There was significant variation by country on LS and SCP. In The Netherlands and Scotland, about $90 \%$ of young people were satisfied with their life, while in Poland and Hungary it was approximately $80 \%$. The percentage of adolescents perceiving communication with both parents as easy was highest in The Netherlands and lowest in Italy, Canada and Scotland. Every day EMC with friends was most frequent in Israel and Scotland, and least frequent in The Netherlands and Germany. Almost half of the adolescents in Germany and Italy exceed the maximum recommended frequency of computer use; in Israel and Poland it is only a quarter.

Univariate analysis of life satisfaction determinants

Table 2 presents LS scores with regard to computer use, EMC with friends and SCP. Adolescents' LS depended on the amount of time spent on the computer: Adolescents who reported more hours per day spent on the computer reported lower LS, consistently in all surveyed countries. LS also depended on SCP: Lower LS was associated with difficulties in communication with parents in all participating countries. Additional analyses conducted with ease of communication with mother and father separately showed similar results.

A more complicated association was found between LS and EMC with friends. In the international sample and in most surveyed countries the relationship was curvilinear. In general, more EMC was related to higher LS. However, the relationship between LS and EMC became negative if EMC exceeded a certain threshold. Additional analyses with quasi-continuous variables showed that this threshold varied by country (Germany 1-2 days/week, Canada and Italy 3-4 days, Scotland and Poland 5-6 days). The relationship between EMC and LS also depended on gender and age. For boys and participants aged 11 and 15, highest LS was observed at 5-6 days of EMC per week, while for girls and participants aged 13 the relationship changed from positive to negative at 3-4 days/week.

In contrast to the curvilinear relationship found in the international sample and in most surveyed countries, a linear relationship was found in The Netherlands and in Israel, though in opposite directions. In The Netherlands, more EMC was associated with lower LS, while in Israel more EMC was associated with higher LS.

Multivariate analysis of life satisfaction

A series of alternative general linear models (GLM) were specified and estimated. In the basic model, estimated for the 


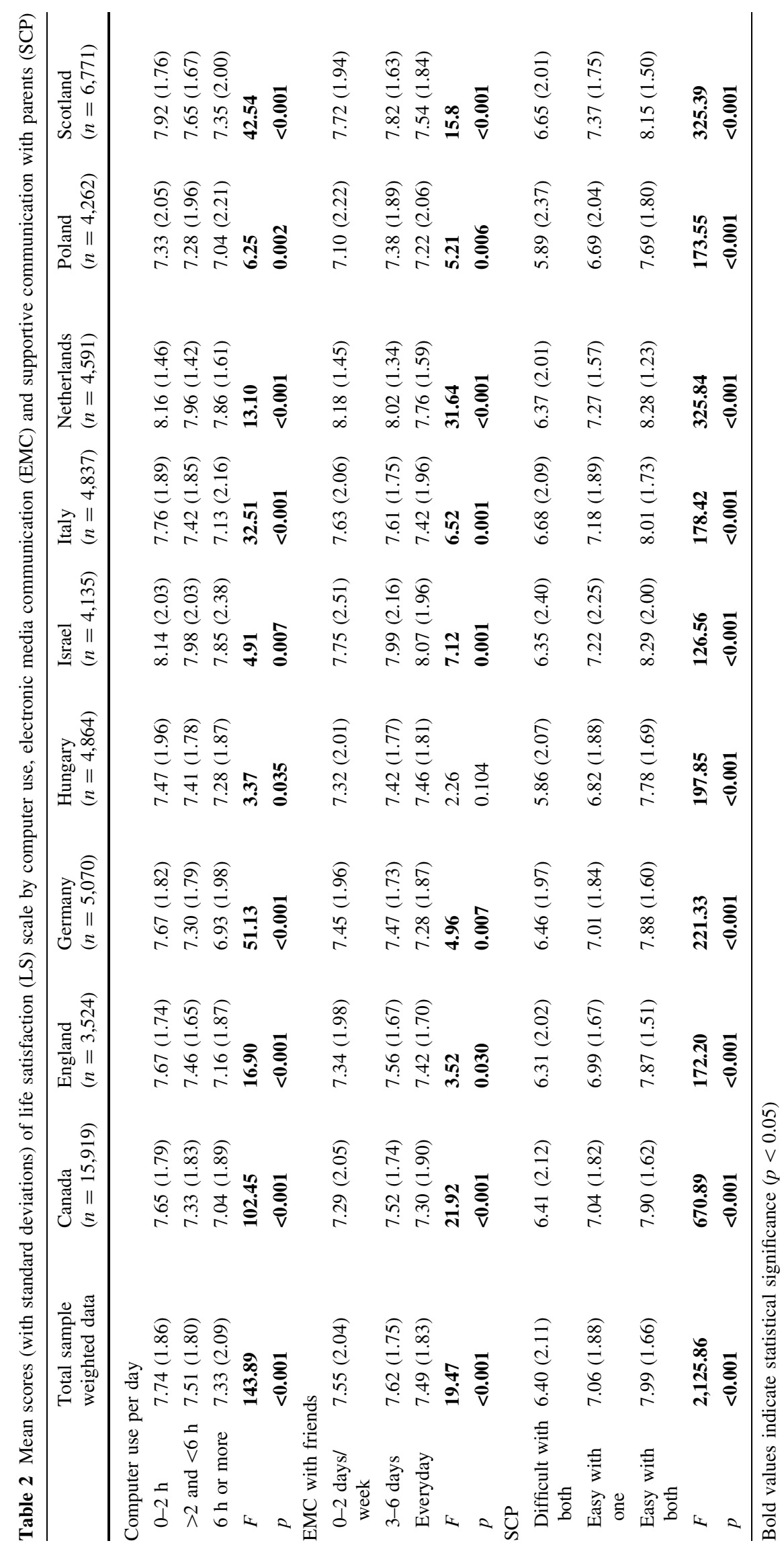




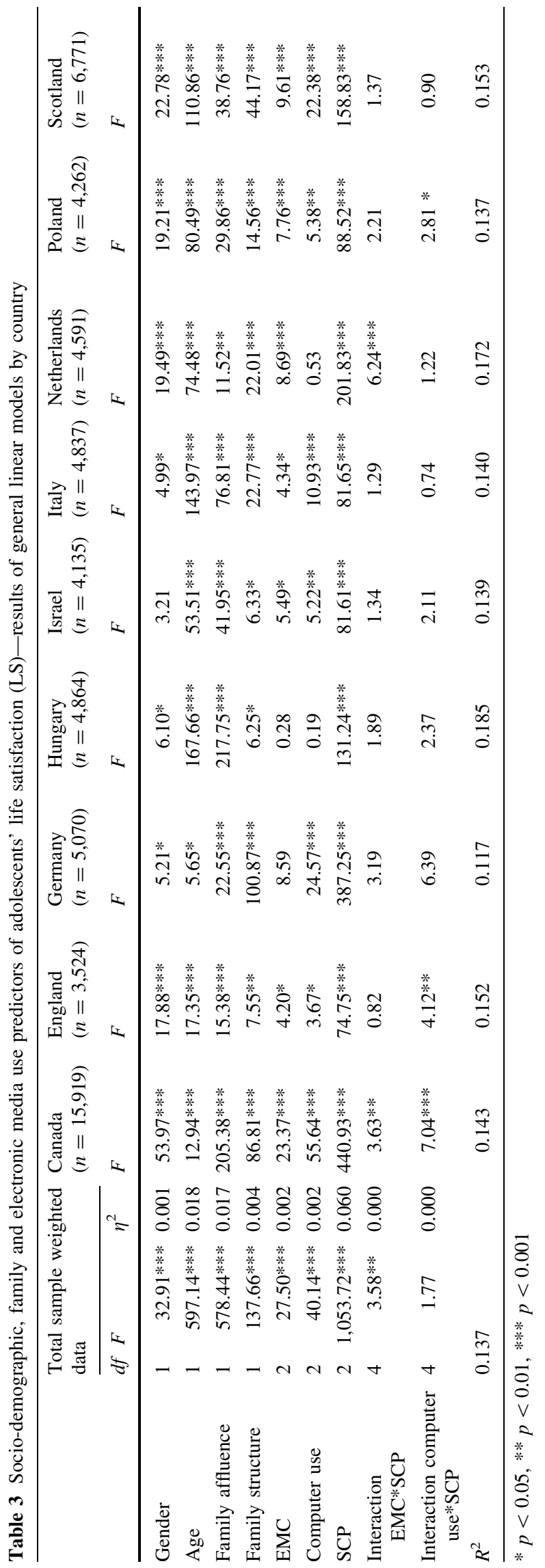

international sample and for each country separately, four control variables (gender, age, family affluence and structure), three explanatory variables (computer use, EMC, and SCP), and two interactions (computer use by SCP, EMC by SCP) were included (Table 3). In the final model for the international sample, all explanatory variables and one interaction $(\mathrm{EMC} \times \mathrm{SCP})$ were significantly associated with LS $\left(R^{2}=0.137\right)$. Additional GLM models estimated for boys and girls separately revealed a significant computer use by SCP interaction for boys $[F(4,15588)=2.81, p<0.05]$. Models estimated for each age group separately only showed a significant computer use by SCP interaction for the 15-yearold adolescents $[F(4,11292)=2.40, p<0.05]$.

GLM models estimated in different regions showed many similarities: age and family characteristics were strong and significant predictors of adolescents' LS in all participating countries. EMC and computer use were associated with adolescents' LS in most countries. In some countries, SCP moderated the relationships between LS and EMC (Fig. 1) or computer use (Fig. 2). The inverse relationship between LS and frequent computer use or using EMC daily was the strongest in adolescents who perceived their communication with both parents as difficult. SCP, therefore, seems to be a protective factor for adolescents' LS.

Two stepwise logistic regression models were estimated (with gender, age, family affluence and structure as control variables) to assess adjusted odds ratios for high LS. In Model 1, the variable combining computer use and SCP was used; in Model 2-EMC with friends and SCP. Difficult communication with one or both parents combined with high computer use ( $>2$ h/day) or daily EMC with friends were the reference groups. The probability of high LS increased about threefold when communication with both parents was easy and computer use or EMC was low (Table 4). Estimations of Model 1 in different countries revealed similar results. The probability of high LS increased with SCP and low computer use with odds ratio's varying from 2.36 (Poland) to 5.46 (England).

Estimations of Model 2 in different countries revealed similar results. The probability of high LS increased with SCP and low EMC use with odds ratios varying from 1.90 (Israel) to 3.36 (Germany), except for The Netherlands $(\mathrm{OR}=8.05)$.

\section{Discussion}

We analyzed associations of EM use with LS in a large sample of adolescents from nine countries as well as the possible moderating role of supportive communication with parents. Associations between EM use and LS differed between countries, and these associations were generally of lower magnitude than associations between 
Fig. 1 Adolescents' life satisfaction—statistically significant interactions between electronic media communication and supportive communication with parents (Canada, The Netherlands, 2009/2010)

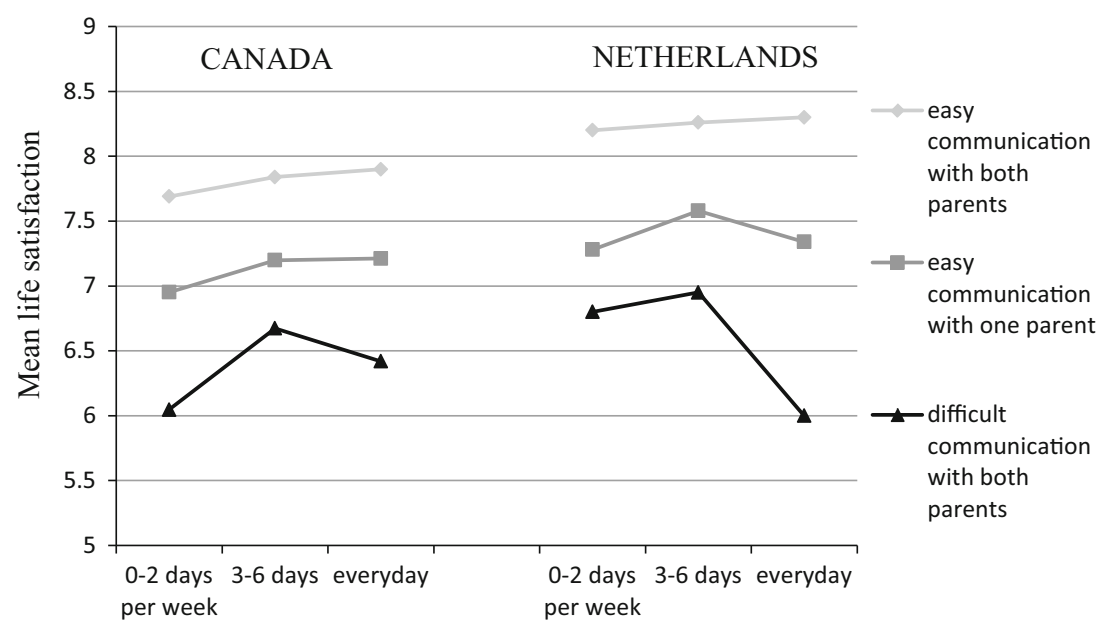

EMC with friends

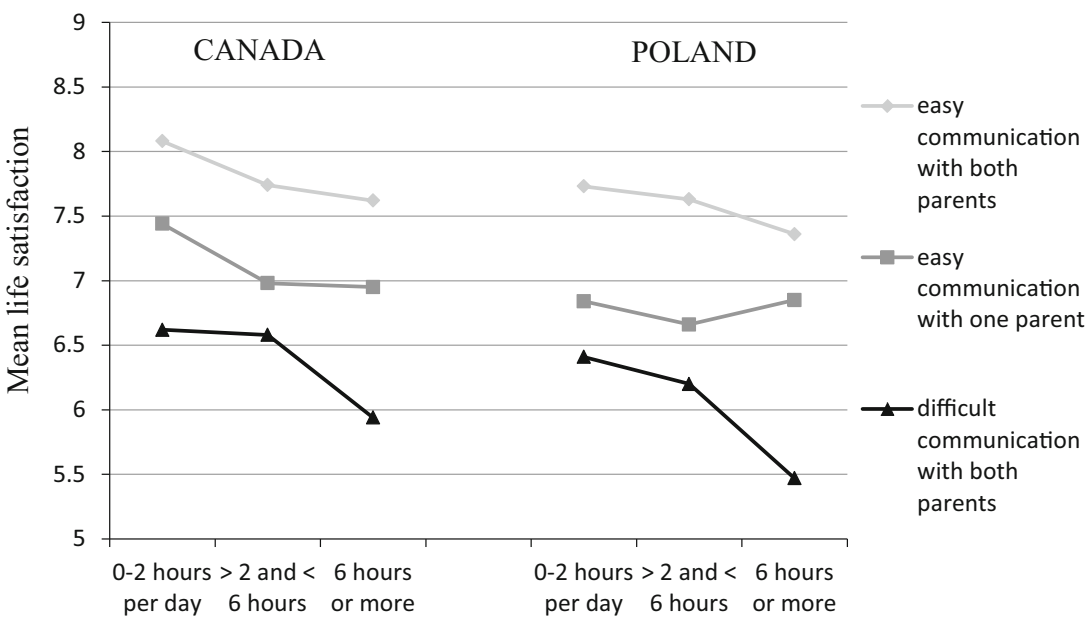

COMPUTER USE
Fig. 2 Adolescents' life satisfaction—selected statistically significant interactions between computer use and supportive communication with parents (Canada, Poland, 2009/2010)
The results demonstrated greater variation for EMC with friends. This difference between computer use in general and EMC with friends may be explained by the type of applications used, for example, communication versus noncommunication applications. As Valkenburg and Peter (2011) emphasize, the effects of online communication with friends (positive) differ from the effects of gaming, surfing or chatting with strangers (negative). Computer use and EMC should, therefore, be considered separately in terms of their relation with LS.

Although EMC with friends is generally thought to have positive effects on intimacy and well-being (Valkenburg and Peter 2009; Manago et al. 2012) some studies also found the amount of EMC to be related to psychological problems and lower LS (Stepanikova et al. 2010; Ferguson et al. 2014; Rosen et al. 2014). In our study, we found a curvilinear relation. With the exception of Israel and The Netherlands, adolescents reporting very low or very high EMC with friends had the lowest LS, while the frequency

Rosen et al. 2014). 
Table 4 Results of logistic regression models (gender, age, family affluence and structure as control variables)—adjusted odds ratios for the prediction of high life satisfaction (LS)

\begin{tabular}{|c|c|c|c|c|c|}
\hline Variable & Analyzed group & Reference group & $p$ & OR & $95 \%$ IS \\
\hline \multirow[t]{4}{*}{$\begin{array}{l}\text { Computer use } \\
\quad \text { (Model 1) }\end{array}$} & & $\begin{array}{l}\text { Low SCP with one or both parents } \\
\text { and computer use more than } 2 \mathrm{~h} / \text { day }\end{array}$ & & & \\
\hline & $\begin{array}{l}\text { High SCP with both parents and computer } \\
\text { use } 0-2 \mathrm{~h} / \text { day; }\end{array}$ & & $<0.001$ & 3.43 & $3.12-3.77$ \\
\hline & $\begin{array}{l}\text { High SCP with both parents and computer } \\
\text { use more than } 2 \text { h/day }\end{array}$ & & $<0.001$ & 2.86 & $2.65-3.07$ \\
\hline & $\begin{array}{l}\text { Low SCP with one or both parents and } \\
\text { computer use } 0-2 \mathrm{~h} / \text { day }\end{array}$ & & $<0.001$ & 1.18 & $1.08-1.30$ \\
\hline \multirow[t]{4}{*}{$\begin{array}{l}\text { EMC with friends } \\
\text { (Model 2) }\end{array}$} & & $\begin{array}{l}\text { Low SCP with one or both parents } \\
\text { and everyday EMC with friends }\end{array}$ & & & \\
\hline & $\begin{array}{l}\text { High SCP with both parents and EMC with } \\
\text { friends less than everyday }\end{array}$ & & $<0.001$ & 2.73 & $2.51-2.98$ \\
\hline & $\begin{array}{l}\text { High SCP with both parents and everyday } \\
\text { EMC with friends }\end{array}$ & & $<0.001$ & 3.03 & $2.65-3.07$ \\
\hline & $\begin{array}{l}\text { Low SCP with one or both parents and } \\
\text { EMC with friends less than everyday }\end{array}$ & & 0.781 & 0.99 & $0.91-1.07$ \\
\hline
\end{tabular}

of EMC that was associated with the highest LS differed by country, gender and age group. Our findings, therefore, suggest that there is a (country-specific) optimal frequency of EMC with friends.

This perspective supports the view that using EM to communicate with friends is normative among adolescents and not complying with this norm may compromise quality of social interactions, as excessive EMC does. Analyses, however, also revealed that the 'optimal' frequency of EMC seemed to be higher in boys than in girls, while girls in general use EMC more frequently.

An alternative explanation would be that EMC with friends mirrors non-virtual friendships and that those with few contacts, therefore, use EM less for communication. Other research in fact showed that EMC with friends was positively related to number of close friends and face-toface contacts (Kuntsche et al. 2009). Youth with exceedingly frequent EMC also may have more but less intimate friendships and, therefore, report a lower LS. Furthermore, especially frequent EMC could be a sign of a compulsive use in some adolescents.

The optimal frequency of EMC with friends varied in line with the average country frequency. In countries where every day EMC was less frequent, the optimal frequency tended to be lower (Germany, The Netherlands) while in countries with the highest frequency of daily EMC (Israel, Scotland) higher frequencies seemed optimal. This finding supports the assumption that the optimal level of EMC in adolescents corresponds to the norm.

Cross-country differences in the associations of EM and LS might be explained by differences in the functions EM serves for adolescents from different countries or different types of EM that are predominately used for communication with friends. We cannot, however, identify these possibilities because different types and functions were not assessed. Moreover, there are cultural differences in average LS as well as differences in relevance of different life domains for LS that may also influence the strength of the associations (Park 2004). Another explanation for the between-country variation in associations might be that countries differ in the number of opportunities youths have to contact friends in person versus virtually using EMC (for example due to different school schedules and spatial spread of housing spaces). In countries where there are less opportunities to meet face-toface, EMC may be a more common alternative, but more frequent EMC may also be necessary to maintain close relationships and well-being.

Between-country variation in EM effects may explain some of the inconsistent results relating to the associations of EM use and LS reported in the literature. Nevertheless, previous studies also differ markedly in the specific technologies and functions that were studied in relation to LS and mental health. Further cross-national studies with more differentiated measures of technologies used, norms, motives and functions could help to explain country-specific effects. Associations between EM use and LS, however, were generally small, compared to effects of socio-demographic variables and parental communication.

\section{Supportive communication with parents}

Multiple parental factors are assumed to be an important protective resource for adolescents' LS and other healthrelated outcomes (Park 2004; Antonogeorgos et al. 2013) with ease of family communication being seen as an 
important determinant of adolescent health. Concerning the positive associations between SCP and LS, our study supports this assertion. Furthermore, our results are in line with other research findings demonstrating that supportive parent-adolescent communication is an important resource for LS during adolescence (Moreno et al. 2009; Levin and Currie 2010; Piko and Hamvai 2010; Elgar et al. 2013).

In our study, SCP seemed to be more important for LS than EMC with friends. This finding is consistent with other research showing that parental support or communication quality has a more significant effect on psychological well-being than peer relations (Helsen et al. 2000; Moreno et al. 2009). Positive effects of parent relations are thought to evolve particularly through a buffering effect on stress, specifically, as a resource for coping with potential stressors (Levin and Currie 2010). Our result that SCP moderated the associations between EM use and LS confirms this view, since in general negative media effects were smaller-especially concerning EMC - when communication with parents was rated as easy.

An explanation for between-country differences in the moderator effects could lie in the measure itself, as we asked for talking about "things that really bother you" without specifying topics. It might be that there are cultural differences in communication style. However, associations of SCP and LS were consistently found cross nationally.

Concerning health promotion and prevention, our results indicate that prevention strategies regarding excessive media use in adolescence should differentiate between EMC with friends versus other activities. In terms of EMC, programs should not rely on 'one size fits all' recommendations on maximum use, but have to take into account the country-specific patterns of use in this age group. More research is needed to disentangle the factors that determine under which conditions a certain amount of EMC may become detrimental to well-being and why. Parents and teachers should be aware that EMC with friends nowadays is a normative way of communication but not per se a sign of less intimate friendships or loneliness. Furthermore, instead of demonizing use of EMC, parents should be aware of the outstanding role their own relationship with their children has for youths' well-being.

\section{Strengths and limitations}

A major advantage of the HBSC study is that it allows for cross-national comparisons based on a standardized research protocol and uniform measurements. Since EM measures markedly differ between studies, international comparisons are rare. Furthermore, the study uses large, nationally representative samples and all included measures are validated. We found no other study that examined the moderating role of $\mathrm{SCP}$ on the associations between EM and LS.

A main limitation of the study is its cross-sectional design that does not allow for causal inferences. Moreover, all measures are based on self-reports, and this may overestimate associations. Because the HBSC study assesses a wide range of health-relevant variables, measurements have to be short and often comprise of one-item-measures. Such a situation occurred with the SCP measure, where only information about easiness of communication was assessed. However, many previous studies validated this question as a good measure of the respondent's relationship with parents (Currie et al. 2012). Different forms of EMC with friends (i.e., texting, phone calls, e-mailing or using social network sites) or different functions of computer use were not distinguished. Further research is required to study more specific effects and to learn how these effects may interact with SCP.

\section{Conclusion}

Our study confirms the important role of communication with parents for adolescents from different countries, and implies a buffering of negative effects of EM use on LS in early adolescents. While higher computer use in general was related to lower LS, there seems to be an optimal frequency of EMC with friends that seems to relate to the typical country-specific frequency of use. Nevertheless, compared to ease of parent-adolescent communication and socio-demographic characteristics the effect sizes of EM were rather small.

\section{References}

Adiele I, Olatokun W (2014) Prevalence and determinants of internet addiction among adolescents. Comput Hum Behav 31:100-110

American Academy of Pediatrics (2001) Children, adolescents, and television. Pediatrics 107(2):423-426

Antonogeorgos G, Panagiotakos DB, Grigoropoulou D, Papadimitriou A, Anthracopoulos M, Nicolaidou P, Priftis KN (2013) The mediating effect of parents' educational status on the association between adherence to the Mediterranean diet and childhood obesity: the PANACEA study. Int J Public Health 58(3):401-408

Becker MW, Alzahabi R, Hopwood CJ (2013) Media multitasking is associated with symptoms of depression and social anxiety. Cyberpsychol Behav Social Netw 16:132-135

Benson J (2011) Psychiatrist says video games are influencing youth and not for the better. The day. http://www.theday.com/article/ 20110602/NWS01/306029399

Boyce W, Dallago L, Settertobulte W (2004) Socioeconomic inequality. In: Currie C, Roberts C, Morgan A, Smith R, Samdal O, Rasmussen Barnekow V (eds) Young people's health in context: international report from the HBSC 2001/02 survey. WHO Regional Office for Europe, Copenhagen, pp 13-25

Bradshaw J, Keung A, Rees G, Goswami H (2011) Children's subjective well-being: international comparative perspectives. Child Youth Serv Rev 33(4):548-556 
Brooks FM, Magnusson J, Spencer N, Morgan A (2012) Adolescent multiple risk behaviour: an asset approach to the role of family, school and community. J Public Health (Oxf) 34(Suppl 1):i48 i56

Chahal H, Fung C, Kuhle S, Veugelers PJ (2013) Availability and night-time use of electronic entertainment and communication devices are associated with short sleep duration and obesity among Canadian children. Pediatr Obes 8(1):42-51

Currie C, Zanotti C, Morgan A, Currie D, Looze de M, Roberts C, Samdal O, Smith ORF, Barnekow V (eds) (2012) Social determinants of health and well-being among young people: health behaviour in school-aged children (HBSC) study: international report from the 2009/2010 survey. Health policy for children and adolescents, vol 6. WHO Regional Office for Europe, Copenhagen

Deniz L (2010) Excessive internet use and loneliness among secondary school students. J Instr Psychol 37:20-23

Diener E, Emmons RA, Larsen RJ, Griffin S (1985) The satisfaction with life scale. J Pers Assess 49(1):71-75

Elgar FJ, Craig W, Trites SJ (2013) Family dinners, communication, and mental health in Canadian adolescents. J Adolesc Health 52(4):433-438

Ferguson CJ, Muñoz ME, Garza A, Galindo M (2014) Concurrent and prospective analyses of peer, television and social media influences on body dissatisfaction, eating disorder symptoms and life satisfaction in adolescent girls. $\mathrm{J}$ Youth Adolesc 43(1): $1-14$

Finne E, Bucksch J, Lampert T, Kolip P (2013) Physical activity and screen-based media use: cross-sectional associations with healthrelated quality of life and the role of body satisfaction in a representative sample of German adolescents. Health Psychol Behav Med 1(1):15-30

Helsen M, Vollebergh W, Meeus W (2000) Social support from parents and friends and emotional problems in adolescence. J Youth Adolesc 29(3):319-335

Iannotti RJ, Janssen I, Haug E, Kololo H, Annaheim B, Borraccino A (2009) Interrelationships of adolescent physical activity, screenbased sedentary behaviour, and social and psychological health. Int J Public Health 54(S2):191-198

Jackson LA, von Eye A, Fitzgerald HE, Witt EA, Zhao Y (2011) Internet use, videogame playing and cell phone use as predictors of children's body mass index (BMI), body weight, academic performance, and social and overall self-esteem. Comput Human Behav 27(1):599-604

Johnson GM (2010) Internet use and child development: validation of the ecological techno-subsystem. Educ Techno Soc 13(1):176-185

Kuntsche E, Simons-Morton B, ter Bogt T, Queija IS, Tinoco VM, de Matos Gaspar, Margarida Santinello M, Lenzi M (2009) Electronic media communication with friends from 2002 to 2006 and links to face-to-face contacts in adolescence: an HBSC study in 31 European and North American countries and regions. Int J Public Health 54(Suppl 2):243-250

Lacy KE, Allender SE, Kremer PJ, Silva-Sanigorski AM, Millar LM, Moodie ML, Mathews LB, Malakellis M, Swinburn BA (2012) Screen time and physical activity behaviours are associated with health-related quality of life in Australian adolescents. Qual Life Res 21(6):1085-1099

Levin KA, Currie C (2010) Family structure, mother-child communication, father-child communication, and adolescent life satisfaction: a cross-sectional multilevel analysis. Health Educ 110(3): 152-168

Levin KA, Currie C (2013) Reliability and validity of an adapted version of the Cantril ladder for use with adolescent samples. Soc Indic Res:1-17

Livingstone S, Haddon L, Görzig A, Ólafsson K (2011) EU Kids online final report. http://www.lse.ac.uk/media@1se/research/ EUKidsOnline
Manago AM, Taylor T, Greenfield PM (2012) Me and my 400 friends: the anatomy of college students' Facebook networks, their communication patterns, and well-being. Dev Psychol 48(2):369-380

Mathers M, Canterford L, Olds T, Hesketh K, Ridley K, Wake M (2009) Electronic media use and adolescent health and well-being: crosssectional community study. Acad Pediatr 9(5):307-314

Mesch GS (2003) The family and the internet: the Israeli case. Soc Sci Q 84(4):1038-1050

Moreno C, Sánchez-Queija I, Muñoz-Tinoco V, Matos MG, Dallago L, Bogt TT, Camacho I, Rivera F (2009) Cross-national associations between parent and peer communication and psychological complaints. Int J Public Health 54(S2):235-242

Mößle T, Kleimann M, Rehbein F, Pfeiffer C (2010) Media use and school achievement-boys at risk? $\mathrm{Br} \mathrm{J}$ Dev Psychol 28(3):699-725

Ofcom (2014) Children and parents: media use and attitudes report. http://stakeholders.ofcom.org.uk/binaries/research/media-liter acy/media-use-attitudes-14/Childrens_2014_Report.pdf. Accessed 3 Oct 2014

Page AS, Cooper AR, Griew P, Jago R (2010) Children's screen viewing is related to psychological difficulties irrespective of physical activity. Pediatrics 126(5):e1011

Park N (2004) The role of subjective well-being in positive youth development. Ann Am Acad Pol Soc Sci 591(1):25-39

Piko BF, Hamvai C (2010) Parent, school and peer-related correlates of adolescents' life satisfaction. Child Youth Serv Rev 32(10):1479-1482

Purcell K (2013) 10 Things to know about how teens use technology. Pew Research Center. http://www.pewinternet.org/2013/07/10/ 10-things-to-know-about-how-teens-use-technology/

Racine EF, DeBate RD, Gabriel KP, High RR (2011) The relationship between media use and psychological and physical assets among third- to fifth-grade girls. J Sch Health 81(12):749-755

Rosen LD, Lim AF, Felt J, Carrier LM, Cheever NA, Lara-Ruiz JM, Mendoza JS, Rokkum J (2014) Media and technology use predicts ill-being among children, preteens and teenagers independent of the negative health impacts of exercise and eating habits. Comput Human Behav 35:364-375

Steinberg L, Morris AS (2001) Adolescent development. J Cogn Educ Psychol 2(1):55-87

Stepanikova I, Nie NH, He X (2010) Time on the internet at home, loneliness, and life satisfaction: evidence from panel time-diary data. Comput Human Behav 26(3):329-338

Sweetser P, Wyeth P (2005) Gameflow. Comput Entertain 3(3):3

Tabak I, Jodkowska M, Oblacińska A (2013) Family meals, support and communication within the family as predictors of teenagers' subjective health and life satisfaction. Pediatr Pol 6(88):533-539

Torsheim T, Eriksson L, Schnohr CW, Hansen F, Bjarnason T, Välimaa R (2010) Screen-based activities and physical complaints among adolescents from the Nordic countries. BMC Public Health 10(1):324

Uttal DH, Meadow NG, Tipton E, Hand LL, Alden AR, Warren C, Newcombe NS (2013) The malleability of spatial skills: a metaanalysis of training studies. Psychol Bull 139(2):352-402

Valkenburg PM, Peter J (2007) Online communication and adolescent well-being: testing the stimulation versus the displacement hypothesis. J Comput Mediat Commun 12(4):1169-1182

Valkenburg PM, Peter J (2009) Social consequences of the internet for adolescents: a decade of research. Curr Dir Psychol Sci 18(1):1-5

Valkenburg PM, Peter J (2011) Online communication among adolescents: an integrated model of its attraction, opportunities, and risks. J Adolesc Health 48(2):121-127 